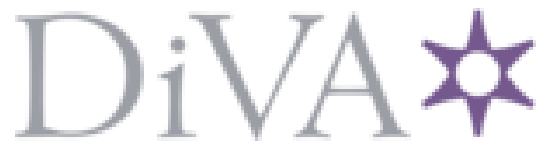

http://www.diva-portal.org

Preprint

This is the submitted version of a paper published in Noûs.

Citation for the original published paper (version of record):

Tersman, F. (2017)

Debunking and Disagreement

Noûs, 51(4): 754-774

https://doi.org/10.1111/nous.12135

Access to the published version may require subscription.

N.B. When citing this work, cite the original published paper.

Permanent link to this version:

http://urn.kb.se/resolve?urn=urn:nbn:se:uu:diva-269714 
This is a pre-peer reviewed version of the article 'Debunking and Disagreement' Noûs 00:0, 2015, 1-21 (Early View), doi: 10.1111/nous.12135, which has been published in final form at: http://onlinelibrary.wiley.com/doi/10.1111/nous.12135/abstract.

\author{
Folke Tersman
}

Uppsala University

\title{
Debunking and Disagreement
}

\section{Introduction}

A familiar way of supporting skeptical doubts about the beliefs in some area, such as ethics or religion, is to provide a "debunking argument" against them. ${ }^{1}$ Another, even more familiar, way is to appeal to the disagreement that occurs in the area. ${ }^{2}$ These types of challenge are often treated separately and there is not much overlap in the literature they have given rise to. Yet, as they pursue the same conclusion - that the target beliefs are not (fully) justified and that we should reduce our confidence in them-one might well wonder how they are related. Are they entirely independent or do they interact in non-trivial and interesting ways? That is the question I shall explore.

What can be gained from such an exercise? The obvious idea is that it might help us to reach a better-informed verdict about the conclusion the arguments jointly seek. For example, if we find that considerations that emerge in the discussion of one of the strategies help to block objections to the other, this should be of interest to anyone who wants to assess the skeptic's position. John Rawls has famously stressed that the justification of a philosophical position is "a matter of the mutual support of many considerations, of everything fitting together into one coherent view." (Rawls 1971, 21) Paying attention to how different arguments for skepticism interact is a way of honoring that thought. 
In any case, that there are interdependencies of the indicated type between debunking arguments and arguments from disagreement is precisely what I aim to show. More specifically, I shall focus on moral beliefs and on attempts to debunk such beliefs with reference to an evolutionary account of their origins. ${ }^{3}$ The question is how appeals to disagreement may help such a debunker. ${ }^{4}$ I shall argue that they can provide crucial help. As I will illustrate, there is a gap in the debunkers' strategy - a gap the debunkers need to close. Appeals to disagreement have a crucial role to play because they can help them do just that. The more general upshot is that the areas in which a debunking strategy is most likely to succeed are precisely those that are dominated by diversity of the type arguments from disagreement point to. ${ }^{5}$

The plan is as follows. In the next section, I give a general account of the debunking strategy. In sections 3-5, I articulate the steps I take a debunking argument to involve a bit more carefully, and make some comments about the epistemic assumptions it relies upon. In section 6, I mention a trivial way in which the existence of certain types of disagreement can support the evolutionary debunking argument. In sections 7 and 8 , I proceed by discussing the complication in the debunking strategy (the "gap") that provides the background of my main suggestion about how facts about disagreement can help the debunker. The suggestion is elaborated in section 9. In section 10, finally, some concluding remarks are made.

\section{Debunking arguments: The general idea}

Very roughly, a debunking argument is an argument that challenges the justification of a belief by appealing to a "genealogical claim"; i.e., an empirical claim about its causal origins. ${ }^{6}$ It is this role that is played by the evolutionary account of our moral beliefs in the specific argument that I shall discuss. 
The genealogical claim is supposed to undermine the justification of the target beliefs via assumptions to the effect that the process to which it attributes the beliefs is defective in some epistemically relevant way. This characterization of the debunking strategy is congenial with the one offered by Guy Kahane. He takes a debunking argument to have the following form:

Causal premise. S's belief that $p$ is explained by $\mathrm{X}$.

Epistemic premise. $\mathrm{X}$ is an off-track process.

Therefore

S's belief that $p$ is unjustified. (Kahane $(2011,106)$ )

There may be different ideas about what makes a belief-forming process defective, but it is common to assume, as Kahane does, that it is relevantly defective to the extent that that it is "off-track" or (as some prefer to say) not "truth tracking". ${ }^{7}$ Note that, as it is the justification of a belief that is challenged, and as a true belief can be unjustified, a debunking argument may be successful even if fails to establish the falsehood of the target belief.

This rough characterization raises many questions. The most important concerns what it means for a process to be, or fail to be, "truth tracking". I shall address that question in the next section. However, before proceeding, I want to make a few preliminary remarks.

Some debunking arguments target particular beliefs, or some limited subset of the beliefs in an area. For example, Peter Singer has famously tried to specifically debunk deontological moral beliefs (by attributing them to certain emotional mechanisms or to the Christian past of Western cultures) while trying to leave the credentials of his own, utilitarian, beliefs intact. ${ }^{8}$ In what follows, however, I shall focus on attempts to debunk moral beliefs globally; i.e., on attempts to debunk all of them in one big sweep. ${ }^{9}$ 
Another difference between different instances of the debunking strategy concerns the strength of the conclusion that is sought. A debunker may insist that the (discovery of the) truth of the genealogical claim excludes that the target beliefs are to any extent justified and therefore commands dropping them (or commands ceasing to take their contents to be "literally true"). ${ }^{10}$ Or she may more cautiously think that it merely detracts (albeit significantly) from their justification. Richard Joyce has recently stressed that he takes the latter line. What Joyce wants to show by revealing the evolutionary background of our moral beliefs is merely that our confidence in them should be "dented" (Joyce (2016)). Nothing in my discussion is going to depend on whether we take the evolutionary debunking argument that provides its focus to pursue the stronger conclusion rather than the weaker. However, to simplify matters, I shall concentrate on the more ambitious version.

A third thing to note is that some debunkers throw a further element into the mix. They make their arguments conditional on a specific view about the status of the target beliefs. It is that view that is seen as the real culprit by the debunker and that provides the ultimate target of her argument. In the case of moral beliefs, this role is usually played by moral realism, or, more specifically, non-naturalist versions of realism. The idea is that it is the combination of (non-naturalist) realism and the evolutionary account that generates skeptical implications, which in turn is taken to be a reason to reject realism and to adopt a competing meta-ethical view (such as some form of constructivism). For example, Sharon Street uses the debunking strategy in this way to defend her own "Humean" version of constructivism, ${ }^{11}$ on the ground that it avoids the skeptical implications that allegedly are obtained if we combine realism with an evolutionary account. ${ }^{12}$

There is some disagreement about whether some form of realism really has to be an element of the debunking strategy. Richard Joyce stresses that it doesn't (Joyce (2016)) while Kahane seems to have the opposite view. ${ }^{13}$ I am inclined to be more sympathetic to Joyce's 
stance here, but this has no import for the points I want make. My argument to the effect that appeals to disagreement have a crucial role to play in the debunking strategy is supposed to be valid even if realism is the debunker's ultimate target. ${ }^{14}$

\section{Reliability}

According to Kahane's characterization, a debunking argument seeks to establish that the target beliefs are not justified by showing that they are the outcome of a belief-forming process that is not truth tracking. We may accordingly take a debunking argument to involve two steps. The first is the step from the genealogical claim to the intermediate conclusion that the target beliefs are not the product of a truth tracking process. The second is the step from the intermediate conclusion to the claim that the target beliefs are unjustified. I am going to use "reliable" to denote the feature a belief has if it is the outcome of a truth tracking process. ${ }^{15}$ The claim that the target beliefs are not the products of a truth tracking process is therefore equivalent with the claim that they are not reliable. Let us call that claim "No reliability" and the claim that they are not justified "No justification". The suggestion is that a debunking argument instantiates the following schema:

\section{The genealogical claim}

\section{Hence: 2. No reliability}

Hence: 3. No justification

The validity of this schema depends on what "reliable" means. The question is if there is an interpretation that vindicates both steps; both the one from 1 to 2 and the one from 2 to 3 . In this section, I shall offer the interpretation that I think is the most likely to succeed. However, notice that, since my aim is not defend the debunking strategy but merely to explore if there is 
a role for disagreement in it, I am not committing myself to the validity of the schema or to any particular instance of it.

It may be tempting to explicate "reliable" in modal terms, and to assume that beliefs are reliable to the extent that their existence is counterfactually dependent on their truth (i.e., on the truth of their contents). For example, we may insist that our beliefs, to be reliable, must be "sensitive" in the sense that, had the relevant facts been different, our beliefs would have been correspondingly different (i.e., would have had different contents). This is the type of dependency we expect from a bathroom scale. If we learn that it would have indicated that we have the weight that we have even if we had weighed significantly less then we would be reluctant to trust it.

However, the relevance of the modal notion of reliability in the present context can be questioned. The reason is that, in some of the areas that debunkers target (such as ethics and mathematics), the beliefs deal with facts that are metaphysically necessary. If the facts that are posited in an area are necessary then it is arguably trivial that the beliefs in that area are sensitive. For if there is no possible world in which the pertinent facts are different, there is no possible world where the facts are different but where the beliefs remain the same, irrespectively of their causal background. So, the strategy of challenging the sensitivity of such beliefs by appealing to their origins appears doomed from the start.

The above reasoning is part of an argument against attempts to debunk moral (and mathematical) beliefs that has recently been offered by Justin Clark-Doane (Clark-Doane (2015)). Clark-Doane thinks that, to undermine the justification of a set of beliefs in the way debunkers want, one must either show that they are not sensitive or that they are not "safe", where a belief is safe in Clark-Doane's terminology if, given its truth, it could not easily have been false. The sensitivity of our moral belief is, he thinks, ensured by the fact that the relevant facts are necessary, ${ }^{16}$ while their safety is guaranteed by the fact that they could not 
easily have been different. For, given that the beliefs are in fact necessarily true, if they could not easily have been different, then they could not easily have been false. In attempting to illustrate how one could argue that our moral beliefs could not easily have been different, Clark-Doane invokes the very account of their origins to which the evolutionary debunkers appeal; i.e., the evolutionary account. The idea seems to be that, since our moral beliefs are the result of an evolutionary process, they would have been different only if our environment had also been quite different. ${ }^{17}$ So instead of undermining the reliability of our moral beliefs, the genealogical claim invoked by evolutionary debunkers helps to validate it. He concludes that, as the evolutionary account accordingly neither threatens the safety nor the sensitivity of our moral beliefs, it does not undermine them in the way debunkers seek to do.

The most obvious way to respond to Clark-Doane's argument is perhaps to deny that moral facts are necessary in a relevant sense. Alternatively, we may deny that their necessity makes it vacuously true that if the relevant facts had been different then our beliefs would also have been different. ${ }^{18}$ Or we could deny that the evolutionary account excludes that they could not easily have been different. However, the conclusion $I$ think a debunker should draw is rather that she should avoid the modal notion of reliability and adopt an alternative one; a notion that allows us to argue that the target beliefs are not reliable in spite of the fact that there is no possible world in which the facts they represent are different. ${ }^{19}$

The alternative notion I want to propose can be introduced as follows. A belief-forming process is commonly held to be truth tracking to the extent that it generally leads to true beliefs. Arguably, if a belief is caused by such a process then the psychological fact that we have it indicates, or gives us a reason to think, that it (or its content) is true. This is the feature I shall take "reliable" to denote. Thus: 
RELIABILITY: A belief is reliable to the extent that our possession of it indicates, or gives us a reason to think, that it (i.e., its content) is true.

Observational beliefs are often reliable in this sense. Normally, if we have formed the observational belief that $p$, this provides some justification for thinking that $p$, at least unless there is a reason to doubt that the belief was formed in appropriate perceptual conditions. ${ }^{20}$ More importantly in the present context, reliability in this sense is a feature a belief could have or fail to have regardless of whether it is necessarily true. If someone has learned the truth of a complex mathematical theorem from reading a highly accurate textbook, then the history of that belief gives us some reason to trust it. It is therefore reliable in the sense relevant here. If the belief has instead been formed as a result of throwing a dice it is not, regardless of whether it is true, and regardless of if its truth is necessary (and regardless also of if the subject could not easily have held a different one).

\section{A distinction}

Does this notion of reliability have the type of epistemic relevance assigned to it by the debunkers' argument? That is, does the proposed notion of reliability vindicate the two steps of a debunking argument? What I shall say about how references to disagreement might help a debunker has mainly to do with the first step of her argument, which therefore is the one I shall focus on. However, before that, I need to make some remarks also about the second, which is the aim of this and the following section.

The second step is the one that takes the debunker from the claim that the target beliefs are not reliable to the conclusion that they are not justified. How might a debunker defend that step (given the preferred notion of reliability)? That's the question I am going to address. 
Given RELIABILITY, the claim that our moral beliefs are not reliable means that our possession of them does not indicate, or provide a reason to think, that their contents are true. That claim should be distinguished from the stronger claim that our possession of them indicates that they are false. The claims in question can be stated as follows:

A. Neither the fact that we have the moral beliefs that we do have, nor the considerations that are responsible for that fact, makes them likely true.

B. The fact that we have the moral beliefs that we do have and/or the considerations that are responsible for that fact make them likely to be false.

This distinction should be kept in mind when one considers some versions of the debunking argument. For example, consider Sharon Street's argument to the effect that the combination of realism and the evolutionary account leads to skepticism. Street calls the version of the evolutionary account she favors "the adaptive link account", ${ }^{21}$ and seems to think that it leads to skepticism (given realism) because it implies B. According to Street, the account in question commits a realist to thinking that the contents of our moral beliefs have been shaped by forces that have pushed them in a certain direction regardless of if the truth lies in that direction. This does not exclude that the truth actually does lie in that direction. But Street insists that, when we reflect on all other possibilities, we realize that this is very unlikely:

Of course, it is possible that as a matter of sheer chance, some large portion of our evaluative judgments ended up true, due to a happy coincidence between the realist's independent evaluative truths and the evaluative direction in which natural selection tended to push us, but this would require a fluke of luck that's not only extremely unlikely, in view of the huge universe of logically possible evaluative judgments and 
truths, but also astoundingly convenient to the realist. Barring such a coincidence, the only conclusion remaining is that many or most of our evaluative judgements are off track. (Street $(2006,122))$

However, this reasoning is not compelling, as Kevin Brosnan has argued (in (2011)). The evolutionary account may or may not entail A (we shall return to that question). But A does obviously not entail $\mathrm{B},{ }^{22}$ and the references to the "universe of logically possible evaluative judgments and truths" fail to show that the adaptive link account plus realism implies that our moral beliefs are probably false. The adaptive link account allows us to conclude, perhaps, that the conditional probability of our having the moral beliefs that we have, given the assumption that they are true, is not greater than the probability of our having them given their falsehood. However, to get to the further conclusion that they are probably false (on the assumption that we have them) we need priors, as Bayes' theorem makes clear. That is, we need (independently) justified estimates of the probability of the moral claims that constitute the contents of the beliefs and Street provides no such estimates. ${ }^{23}$

\section{From the lack of reliability to the lack of justification}

The upshot of the discussion in section 4 is that a debunker needs to get from the claim that the target beliefs are not reliable (or A) to the conclusion that they are not justified via some path that does not go through B. Is there such a path?

There are epistemological views that seem to vindicate the second step quite

straightforwardly, such as reliabilism. Roughly, according to reliabilism, a belief is justified to the extent that it is caused by process that generally leads to true beliefs. So, if being caused by such a process is necessary for it to be reliable in the sense relevant here then reliabilism implies that, if our moral beliefs are not reliable, they are not justified. However, I would like 
to suggest a different argument through which a debunker may hope to show that the lack of reliability of our moral beliefs undermines their justification.

Given "my" notion of reliability, there are, it seems to me, two assumptions a debunker needs to make. The first is the anti-conservatist view that some beliefs, and specifically the beliefs whose credentials are discussed here, are such that their justification requires some form of positive support. The view in question also implies that the required type of support is of a special type. I am going to call that type "reliability support". A belief has reliability support if it either is itself reliable or if our acceptance of its content $(p)$ can be justified with reference to other propositions $(q)$ that in turn are contents of beliefs that are reliable.

The second assumption the debunker needs to make is that no moral belief has reliability support unless some moral beliefs are reliable. ${ }^{24}$ The two assumptions can be stated thus:

(i) The justification of our moral beliefs requires that they have reliability support.

(ii) If none of our moral beliefs is reliable none of them has reliability support.

Given (i) and (ii), the claim that our moral beliefs are not reliable implies that they are unjustified. Simply put, the idea is that the (alleged) fact that our moral beliefs are not reliable undermines their justification because it signifies the absence of a crucial type of positive support.

Both (i) and (ii) can obviously be questioned. However, in what follows, I shall take them for granted. That is, I shall grant the debunker the step from the claim that the target beliefs are not reliable to the conclusion that they are unjustified, since the question I am interested in is if disagreement has a role to play even if we make that concession. Still, a few supporting remarks might be in order. 
Why is reliability support so important? Suppose that, although none of our beliefs in some area has any reliability support, their contents stand in certain internal coherence relations to one another. We may imagine, for example, that the set is consistent and that its members are ordered in such a way that each either explains or is explained by the assumed truth of the others. We may also imagine that none of the members of the set conflict with anything else we believe or have reason to believe. What, in terms of an assurance that can help to justify the beliefs, could reliability support possibly add to this? Why are the internal relations not enough for us to be justified in accepting the theory that the set may contain?

The intuition that fuels (i) has been nicely brought out by Hartry Field, with his wellknown story about a remote village in Nepal (Field $(1989,26))$. Suppose that someone happens to believe various things about this village, such as that an odd number of its inhabitants were born on a Friday, but cannot provide a plausible explanation of their reliability. She has found, for example, that the source of her "information" is a person who has never visited the village nor been in contact with anyone who has. In this case, the person would surely be wise to drop her beliefs,${ }^{25}$ regardless of the fact that their contents are related in such a way that the truth of each of them explains or is explained by the assumed truth of the others. Assuming that the discovery that there is no possible explanation of the reliability of the beliefs shows that none of them is reliable, this accords with (i).

What Field seems to have in mind here is the importance of external, independent justification. And that is the type of justification beliefs with reliability support arguably can provide. For if a belief has that feature then the source of our justification for relying on its content is ultimately the psychological fact that it is an object of an attitude. It can therefore provide independent justification for a belief that is not about our attitudes.

Note also that the above reasoning helps to explain the privileged status that is assigned to observations in the sciences. Support from (the contents of) our observations is required for 
a scientific theory to be warranted, and if a theory conflicts with them it is the theory that has to give way rather than the observations (unless they can be explained away). Why? Because the contents of our observations often have reliability support. The contents of our observations have reliability support because the fact that they are the contents of observations is a sufficient ground for relying on them. In so far as this ground is unthreatened by the conflicts that occur between their contents and the theories we want to test against them, it is reasonable to prioritize our observations if such conflicts were to occur.

As for (ii), one obvious objection is that moral beliefs may have reliability support in virtue of the fact that their contents are backed up by the truth of the contents of reliable nonmoral beliefs (perhaps observational ones). But there are familiar problems with that suggestion. One problem is that it raises all the thorny issues in the debate about Harman's well-known challenge against moral realism. ${ }^{26}$ Arguably, a belief, ethical or otherwise, obtains support from some evidence only if it (or its content) is assumed by the best explanation of that evidence. Thus, pursuing the present suggestion requires that one show that moral facts are posited by the best explanation of something observable (at least if we assume that the non-moral contents to which a non-skeptic wants to appeal represent such facts).

Well, these brief remarks obviously need to be extensively elaborated to provide a sufficient justification for (i) and (ii). However, and to repeat, since I am going to grant the debunker the second step of her argument, I shall not discuss the matter any further.

\section{Predicting disagreement}

There are certain rather obvious ways in which appeals to disagreement can help evolutionary debunkers. Before proceeding to my main suggestion about how the arguments interact, I shall briefly consider one such unexciting type of relevance. 
On one proposal about how appeals to disagreement may help a debunker, they do so through supporting the genealogical claim that the debunkers invoke. Obviously, if a genealogical claim predicts disagreement in certain circumstances, then, if the predicted disagreement occurs, this helps to confirm the claim in question. To see how this might work, consider the idea that the moral beliefs that permeate a certain culture can be seen as responses to certain features of the environment in which it has emerged. One version of that idea concerns the evaluation of infanticide, and in particular female infanticide. It has been argued that the reason why female infanticide is approved of in some cultures has to do with the access to protein. The idea is that a shortage of protein leads to a need to regulate the population, which in turn promotes values that support female infanticide. ${ }^{27}$ This idea suggests that we will find different attitudes to female infanticide in different cultures, depending on the access to protein. Thus, if such differences can be observed, it helps to confirm the theory in question.

The fact that disagreement can play this role in a debunking argument illustrates one way in which disagreement can be seen to have skeptical implications. In fact, the most famous version of the argument from disagreement of them all-Mackie's "argument from relativity" - may be understood along those lines. Mackie writes:

[T] he argument from relativity has some force simply because the actual variations in the moral codes are more readily explained by the hypothesis that they reflect ways of life than by the hypothesis that they express perceptions, most of them seriously inadequate and badly distorted, of objective values. (Mackie $(1977,37)$

What Mackie is offering here is (a fragment of) a rudimentary theory about why we have the moral convictions that we have. The idea is, as Mackie puts it, that "people approve of 
monogamy because they participate in a monogamous way of life" rather than the other way round. Now, according to Mackie, his way of life-theory provides a better explanation of the diversity than competing explanations that presuppose the existence of moral facts. The diversity accordingly provides evidence for the way of life-theory and therefore also, Mackie suggests, for concluding that there are no moral facts and that all our (positive) moral beliefs are false (which is the upshot of Mackie's well known "error theory").

Upon closer examination, however, it might not be obvious how the explanatory success of the way of life-theory is supposed to support the error-theory. After all, although it doesn't posit the existence of moral facts, ${ }^{28}$ it doesn't seem to presuppose their non-existence either. Presumably, a moral disagreement could be a response to the existence of different ways of life regardless of whether there are any moral truths. On one suggestion, the reason why it still strengthens the error-theoretical position is that, as it sees our moral beliefs as responses to the ways of life in which we participate, it allows us to explain the possession of them without assuming that any of them is true, which in turn, arguably, undermines the justification we have for believing that such truths exist. That our moral beliefs are best explained without assuming their truth is exactly what debunkers such as Joyce tries to show by invoking an evolutionary account. And it is that (alleged) fact that in turn is supposed to undermine their justification. So, on this construal, Mackie's argument is quite straightforwardly a version of the debunking strategy. ${ }^{29}$

However, this reasoning at best manages to secure a rather contingent role for disagreement in the debunking strategy. After all, the genealogical claims that debunkers invoke predict all sorts of facts, and the existence of any of those facts may help to confirm them. For example, both Mackie's way of life-theory and the evolutionary account lead us to expect, not only that there is going to be some divergence in peoples' moral convictions, but also some amount of overlap. So, just as the occurrence of disagreement or diversity can help 
a debunker to confirm her genealogical claim so can, on the present suggestion, the existence of agreement and consensus.

\section{Accommodating the genealogical claim}

The point I want to make, however, is that there is a more decisive role for disagreement to play. This role does not concern the debunkers' genealogical premise but rather the first step of her argument (the step from the genealogical claim to the thesis that the target beliefs are not reliable). The point of departure of my proposal is the important observation that the genealogical claim the evolutionary debunkers invoke is not sufficient by itself to secure the conclusion that our moral beliefs are not reliable.

As I just wrote, Joyce stresses that an evolutionary account of the origins of our moral beliefs has skeptical implications because it is consistent with the systematic falsehood of those beliefs. ${ }^{30}$ On the evolutionary account, very roughly, our moral beliefs are manifestations of dispositions that have evolved through natural selection. The dispositions have been selected, moreover, because the beliefs generate behavior that is, in certain situations, fitness-enhancing. Why are we disposed to think that free riding is morally objectionable? Roughly, according to the evolutionary account, because avoiding free riding helped our ancestors to cope with certain difficult coordination problems. And the thing to note is that both the evolutionary theory itself and the further, auxiliary assumptions we have to invoke to make the explanation work are neutral towards moral issues. It is this neutrality that ensures that it is consistent with the falsehood of the target beliefs.

However, even if we grant that the evolutionary account has this feature, and moreover that the account is superior to its competitors, it still does not follow that the target beliefs are not reliable. The reason is that it merely rules out one potential ground for attributing reliability to them and that there may be others. That is, the fact that the best explanation of 
the possession of a belief does assume the truth of its content may be sufficient for concluding that it is reliable, since our having it in such a case gives us a reason to think it true. That particular ground is obviously excluded by the moral neutrality and alleged superiority of the evolutionary account, in the case of our moral beliefs. However, as it is not a necessary condition, this does not in turn settle the question about their reliability.

The point can be illustrated by the availability of so-called "third-factor" explanations of the reliability of our moral beliefs. Consider David Enoch's version of this strategy (Enoch (2010, for related suggestions, see Brosnan (2011), Schafer (2010) and Skarsaune (2011)). Enoch notes that the thesis that our moral beliefs are reliable posits a correlation between our moral beliefs and the facts in virtue of which they are supposed to be true. In an attempt to defend the thesis in question, he suggests an explanation of the correlation.

If the facts belonging to one set ( $a$-facts) are correlated with those that belong to another set ( $b$-facts) we may try to explain this either by arguing that $a$-facts cause $b$-facts or vice versa. However, the idea behind the third-factor strategy is to instead point to an external factor that is supposed to be responsible for both types of facts. Let us in what follows focus on "rightness beliefs"; i.e., beliefs to the effect that certain types of actions are morally right. According to the evolutionary account, we are disposed to have the rightness beliefs we have because the actions they prescribe increase the agent's fitness. It often does so, moreover, through helping the agent or her kin to survive. It is that fact-the fact that the actions in questions promote survival - that is the third factor to which Enoch appeals.

How does the explanation work? An important element is a further assumption that Enoch invokes, namely the substantively moral claim that "survival or reproductive success [...] is at least somewhat good" (Enoch $(2010,430))$. The claim is clarified as follows:

Not, of course, that it is always good, or that its positive value is never outweighed by 
other considerations, or even that it is of ultimate or of intrinsic value, or anything of the sort. Furthermore, I am not asking you to assume that the evolutionary "aim" is of value because it is the evolutionary aim. All I will be relying on is the assumption that survival (or whatever) is actually by-and-large better than the alternative (430).

Given this assumption, we can reason as follows. On the evolutionary account, the factor that explains our rightness beliefs is the fact that the actions they ascribe rightness to tend to promote survival. However, given the view that survival is good, this factor also tends to make the actions right, at least if we make the additional assumption that the fact that an act promotes the good counts in favor of its rightness. Thus, the same factor that is supposed to be responsible for the existence of our rightness beliefs - that the actions they prescribe promote survival - is also, at least partially, responsible for their truth.

Enoch thinks that his account suggests that many of the beliefs we are endowed with by evolution are at least "somewhat in line with the normative truths" $(2010,430) .{ }^{31} \mathrm{He}$ concedes that the level of reliability we can squeeze out is not overwhelming, as he thinks that it merely suggests that the moral beliefs we have been endowed with through evolution are "reasonably good starting-points" that are not "too far off". However, that conclusion is arguably sufficient to avoid the type of radical skepticism Street and others think a realist is committed to, given the evolutionary account. Remember that Street thinks that realists are committed to the view that, if our moral beliefs are true, this is just a matter of fluke or chance. So if the likelihood can be shown to be slightly greater than chance, on the basis of the evolutionary account, that is presumably enough to refute her claim. Moreover, Enoch thinks that we have reason for an even stronger optimism when we consider the additional impact that ordinary reasoning processes may have. He writes: 
Given a starting point of normative beliefs that are not too far-off, presumably some reasoning mechanisms (and perhaps some other mechanisms as well) can get us increasingly closer to the truth by eliminating inconsistencies, increasing overall coherence, eliminating arbitrary distinctions, drawing analogies, ruling out initially justified beliefs whose justificatory status has been defeated later on, etc. $(2010,428)$

It is the combined effect of these factors - the fact that our initial beliefs about what is right and wrong depend on the extent to which they promote survival and the benign effects of subjecting them to a reflective equilibrium-style reasoning process - that are thought to be sufficient for fending off the type of skeptical worries debunkers have.

The salient feature of Enoch's proposal is that it tries to reconcile the reliability of our moral beliefs with the evolutionary account claim by invoking a moral assumption. The assumption in question posits a relation between the facts in virtue of which our moral beliefs are true and the (non-moral) facts to which the evolutionary account attributes them. I am going to call such assumptions "bridge principles". Note that the bridge principle is not in any way supposed to help with the explanation of our moral beliefs. It is an entirely external claim relative to the answer the evolutionary account gives to the question of why we have the moral beliefs that we do have. This is why Enochs's account illustrates how a non-skeptic can accommodate the evolutionary account and still concede both that it is consistent with the systematic falsehood of the beliefs and that it is superior to its competitors.

\section{Burdens of proof}

Joyce concedes that the evolutionary account does not by itself show that the target beliefs are not reliable. In Joyce (2016), he writes: "No one, though, thinks that genealogical empirical data alone can secure a skeptical victory; at most they battle alongside skeptical arguments of 
an a priori metaethical nature." Why does he assume that the auxiliary arguments must be "of an a priori metaethical nature"? The reason seems to be that that he thinks that a bridge principle can help the non-skeptic only if it posits a relation of identity between the relevant non-moral and moral facts. ${ }^{32} \mathrm{He}$ imagines for example that a non-skeptic might appeal to a utilitarian reduction of claims to the effect that actions are right and wrong. I disagree. As far as I can see, such an assumption is unwarranted, and a bridge principle may do the job even if it posits a relation of some other sort (such as a nomologically necessary one).

In any case, the availability of the strategy of invoking a bridge principle makes things messier. Joyce's response to the messiness is to suggest that his evolutionary debunking argument is best seen as a burden of proof-challenge. On this idea, the evolutionary account raises prima facie worries about the reliability of the target beliefs. So, if a non-skeptic suggests that it can after all be reconciled with their reliability, for example in the context of a bridge principle, it is on the non-skeptic to show that this is indeed the case, and that the bridge principle is plausible, rather than on the debunker to show that it is not. Until that task has been shouldered, skepticism is the only viable option..$^{33}$

Regardless of whether it is wise for Joyce to make that move, however, we need to address the question of how a particular attempt to respond to the debunkers' challenge by invoking a bridge principle can be shown to be satisfactory. When can the non-skeptic be said to have shouldered the burden of proof that she allegedly faces? It is in that context appeals to disagreement can be seen to have a crucial role. In the next section, I shall explain why this is so. Before I proceed, however, I need to briefly consider an objection to Enoch's strategy.

The objection questions whether the non-skeptic is really entitled to invoke a bridge principle, at least to the extent that the bridge principle is a substantive moral claim. After all, the viability of such a response presumably presupposes that there is some reason to accept the bridge principle in question. And since the principle in question is a moral claim, this 
presupposition directly conflicts with the conclusion that debunkers are pursuing, namely that no moral belief is justified. Thus, by invoking her bridge principle the non-skeptic seems to blatantly beg the question. Or, as Russ Shafer-Landau puts it, she thereby implicitly assumes that the debunker "has lost the argument before it has even begun" (Shafer-Landau 2012, 32).

But this objection is not persuasive. First, it might just as well be said that it is the debunker who begs the question by denying the non-skeptic the strategy of invoking a bridge principle without any independent argument. As Enoch's proposal illustrates, the validity of the inference from the evolutionary account of the origins of our moral beliefs to the conclusion that they are not reliable rules out the truth of some substantive moral claims (such as the claim that the fitness of an act makes it morally right). So the debunker needs to argue that we have no reason to accept those claims. That we don't have any such reason follows of course from the skeptical conclusion that the debunker seeks, but an argument for that conclusion can obviously not simply take it for granted from the start.

Second, and more importantly, to require that a non-skeptic, when attempting to establish the reliability of our beliefs in an area, must not invoke any beliefs of the target kind is to impose a very strong condition; a condition that invites a more promiscuous type of skepticism. For example, consider perceptual beliefs. We do have an account of the reliability of such beliefs; an account that consists of appeals to the theory of evolution and to assumptions about how our sense organs work and how they interact with our environments. However, this account involves exactly the same circularity as Enoch's does. For the assumptions in which it consists constitute straightforward empirical claims whose justification depends on the credentials of the very beliefs whose reliability it tries to establish. So if we deem Enoch's reasoning illegitimate on account of its circularity, we are committed to the same verdict about our perceptual beliefs. Thus, skepticism looms in that context as well. So in so far as the debunkers' want to defend a type of skepticism that leaves 
the epistemic credential of our perceptual beliefs intact, the circularity that is involved by the strategy of invoking bridge principles does not seem to provide a ground for dismissing it. ${ }^{34}$

\section{Explaining error}

Enoch's response illustrates that the non-skeptic has a greater room for maneuvering than one might initially think. The fact that a non-skeptic can hope to accommodate the evolutionary account by invoking a "bridge principle" creates a gap in the debunkers' argument; a gap through which the non-skeptic might try to sneak out. The debunker needs to close that gap.

The fact that disagreement has a role to play in this context is due to the fact that not just any bridge principle that generates the conclusion that the target beliefs are reliable does the trick for the non-skeptic. After all, given just about any genealogical claim, it is always possible to conjure up a bridge principle that, in combination with the claim, generates that conclusion. For example, if we find that people deem an action to be right to the extent that it has some non-moral feature $\mathrm{F}$, all we have to do to reach the conclusion that our rightness beliefs are reliable is to assume that the F makes it right. This trivial fact is not enough to debunk the debunkers' challenge.

That is, an attempt to accommodate the genealogical claim by invoking a bridge principle counts as a satisfying response to the debunkers' challenge only if it has some plausibility. ${ }^{35}$ How is this talk of "plausibility" to be spelled out? In what follows, I shall suggest three different constraints that a successful instance of the strategy of invoking a bridge principle plausibly must satisfy.

According to the first requirement, the defense must not be self-defeating. A defense is self-defeating in the relevant sense if the truth of the contents of the beliefs whose reliability the non-skeptic hopes to secure are inconsistent with, or provide a compelling reason to reject, the bridge principle it invokes. ${ }^{36}$ That would obviously be a fatal flaw. If the beliefs whose 
reliability we are seeking to defend undermine a crucial element of the defense then it hardly provides the comfort that a non-skeptic needs. In such a case, if it is successful, and thus licenses some trust in the target beliefs, it is also warrant the rejection of the defense. Suppose for example that the bridge principle we invoke is some form of utilitarianism. If the contents of the beliefs whose reliability we seek to establish are best explained by some competing moral theory, then the defense violates the first requirement. ${ }^{37}$

The second requirement can also be said to concern the coherence of the defense in question. It states that it is not enough that the truth of the contents of the beliefs whose reliability is to be established doesn't provide a basis for rejecting the bridge principle. It must also provide some reason to accept it (at least in so far as the bridge principle is a substantive moral claim). The motivation for this requirement may need some explanation.

The underlying idea is that a non-skeptic can plausibly invoke a bridge principle only if she has some justification for it. Now, reconsider the assumption named (ii) in section 5. According to (ii), we are justified in accepting a moral principle only if our belief in it either is itself reliable or if the principle obtains support from the contents of other moral beliefs that are. If we combine (ii) with the idea that a non-skeptic can plausibly invoke a bridge principle only if she has some justification for it, we get the conclusion that a non-skeptic may plausibly invoke a bridge principle only if the set of beliefs whose reliability can be established provides support for that principle.

Of course, in response to this, we may imagine that there is some other source of evidence for the bridge principle; i.e., a source that does not presuppose that any moral beliefs are reliable. But, first, I have already granted the debunker that this is not the case (in connection with the discussion of (ii). And, second, if there is some independent way of confirming moral claims, then the non-skeptic obviously does not have to bother with trying to accommodate the evolutionary account by invoking any bridge principle. Then she could 
resist the debunkers' skeptical conclusion without taking that detour, and I am interested in what happens if there is not such an easy way out.

Notice that the second constraint has an important implication. A non-skeptic might hope to simplify the task she allegedly faces by restricting her defense to moral beliefs that are completely uncontroversial. Examples of such beliefs would be the one that it is wrong to torture babies for fun or the belief that "betterness" denotes a transitive relation. However, this cautionary strategy is ruled out by the second constraint. For platitudes of this type clearly underdetermine the sort of claims she needs to invoke to accommodate the evolutionary account (such as Enoch's assumption about the goodness of survival). Thus, in order provide adequate confirmation of the bridge principle, the beliefs whose reliability the non-skeptic manages to establish must be sufficiently varied and rich. It cannot merely consist of uncontroversial platitudes. This will have some significance in what follows. ${ }^{38}$

Let us finally consider the third requirement. It is this constraint that most easily allows one to see how disagreement might help the debunker..$^{39}$ It can be introduced as follows.

Suppose that we attribute the alleged reliability of our moral beliefs to the influence of a factor $\mathrm{X}$ in their causal background. Suppose also that we find that the set of all beliefs that can be attributed to $\mathrm{X}$ contains many conflicts and inconsistencies. ${ }^{40}$ We may imagine for example that, although both A's and B's moral beliefs can be attributed to X (where X, perhaps, consists of some complex set of evolved dispositions), they disagree about most moral issues. Then we have a prima facie problem. $\mathrm{X}$ is arguably reliability-conferring only if the beliefs for which $\mathrm{X}$ is responsible are mostly true. So if the set of beliefs for which $\mathrm{X}$ is responsible contains many conflicts then the assumption that $\mathrm{X}$ is reliability-conferring is hard to sustain. ${ }^{41}$ What we must do, it seems, to restore confidence in the assumption that $\mathrm{X}$ is reliability-conferring is to provide a "theory of error" for some of the conflicting beliefs; i.e., an account of why X, in those particular cases, have led to falsehood (which is not equally 
applicable to the other cases). We may blame the errors, for example, on some independent factor Y whose influence has sapped the (alleged) reliability of the relevant process and interfered with the impact of $\mathrm{X}$ in an unfortunate way. This is what we do in the observational case by blaming recalcitrant observations on bad lighting conditions, etc.

These comments provide the background of the third requirement. Suppose that our defense of the reliability of our moral beliefs attributes it to some aspect of their causal background that is indeed shared by many conflicting beliefs. Then the third requirement implies that the defense is plausibly only if it is provides the basis of a compelling theory of error for (some of) those conflicting beliefs. In other words, a defense of the reliability of the target beliefs is plausible only if it contains resources for plausible ways to explain away the disagreements. What the non-skeptics needs to be able to do is to argue compellingly either that the conflicting beliefs cannot be seen as products of the relevant process or that they have also been influenced by some disturbing factor. That is, they need to argue both that the allegedly disturbing factor has in fact been present in the relevant cases (but not in the others) and that it $i s$ indeed disturbing. In the case of observational beliefs, this condition is clearly satisfied, since our account of their reliability does indeed provide a basis for thinking that bad lighting interfere with the process that in other cases leads to true beliefs.

The third requirement means that the plausibility of defense of the reliability of our moral beliefs of the type we are now considering is going to depend on which types of disagreements that actually exist. In the case of some disagreements, it might be easy to explain them away. For example, Enoch can plausibly attribute some conflicting beliefs to the lack of competence in the search for coherence, due to, say, tendencies to reason in a fallacious way, or to a lack of imagination, etc. However, if there are disagreements where no such shortcomings are involved, such as disagreements between trained philosophers perhaps, 
the task is more difficult, and the third requirement might well turn out to be violated. This is why appeals to disagreement might play a crucial dialectical role in the debunkers' strategy.

If we combine the third constraint with the second, moreover, we get an interesting result. Let us say that a moral disagreement is "radical" if it cannot be explained away in any of the ways mentioned above; i.e., by attributing it to some cognitive shortcoming (fallacious reasoning, lack of imagination, etc). Now, a defense of the reliability of the target beliefs of the type we are considering meets the second constraint only if the set of beliefs whose reliability the non-skeptic is trying to establish is sufficiently rich and varied. And it meets the third constraint only if it represents disagreements about the claims that constitute their contents as being non-radical. When combined, these requirements entail that a defense is plausible only if it generates the conclusion that there is a sufficiently rich and varied set of moral claims about which there is no radical disagreement.

This is an interesting result because what it in effect means is that a non-skeptic who tries to shoulder the burden of proof Joyce thinks that she faces must also, en passant, provide a response to the most influential versions of the argument from moral disagreement. The advocates of those versions try, just as debunkers, to establish skeptical conclusions, and it is to the existence of radical moral disagreements that they appeal. It is not obvious that the occurrence of radical moral disagreement really does have any skeptical conclusions. However, both the advocates and the critics of arguments from disagreement usually acknowledge that if the existing disagreement is not radical it does not pose any skeptical threat. ${ }^{42}$ Thus, if a particular instance of the strategy of attempting to accommodate the evolutionary account by invoking a bridge principle can be shown to satisfy all three constraints stated above, those versions of the arguments from disagreement have also been met. This further illustrates how deeply entangled the two skeptical strategies are. 
In any case, the main suggestion in this section can be summarized as follows. Debunkers hold that an evolutionary account of our moral beliefs undermines their reliability. A nonskeptic can respond by invoking a bridge principle that potentially allows her to reconcile the account in question with the reliability of the beliefs. The debunker needs some way of tackling that strategy and of blocking that response. In this section, I have identified three types of complaints she can reasonably have; i.e., three conditions that a non-skeptic response of the pertinent type must satisfy. It is the third condition that ensures the relevance of disagreement. For, depending on its nature, it potentially rules out that any instance of the strategy satisfies that condition. Since disagreement merely provides one ground for complaints out of three this is not enough to conclude that it is strictly speaking essential to the debunkers' strategy. However, as the first conditions arguably are easier to satisfy it is hard to see how a debunker can do without it. ${ }^{43}$

\section{Conclusion}

The fact that debunkers can turn to the argument from disagreement for help is of course not a big surprise. After all, both types of challenge basically pursue the same, skeptical conclusion. What I have tried to show, however, is that they are related in a more intimate way. It is not just so that the nature of the disagreement that occurs in the target area provides separate support for the debunkers' position. Rather, appeals to disagreement may be important for the debunkers' challenge to work at all. What debunkers request from non-skeptics is the ability to provide a positive account of the reliability of the challenged beliefs. The genealogical claim that the debunkers adduce is meant to narrow down the options that are available to the non-skeptic who is trying to meet this request. For, if the claim in question can be confirmed, the account the non-skeptic produces must be made consistent with it. In other words, the genealogical claim is supposed to present a constraint that is hard to satisfy. However, the 
strategy of invoking bridge principles threatens to neutralize that constraint and to render it toothless. So the debunker needs a further constraint. This is where disagreement enters the dialectic. For, depending on its nature, it undermines the chances of meeting such a further constraint; a constraint that cannot se easily be dodged by invoking a bridge principle. That is why we should discuss the challenges in tandem.

I mentioned in the beginning Rawls' view that the justification of a philosophical position is "a matter of...everything fitting together into one coherent view." (Rawls 1971, 21). We often pay lip service to this idea. However, in practice it is not always treated with the respect it deserves. Instead, the arguments relevant to a position are discussed one at a time, under the implicit assumption that each of them is intended to be able to establish the position by itself. When it is found, unsurprisingly, that it fails to do so one forgets about it and moves on to the next. This is understandable and may in some cases be practical, to avoid getting stuck. Yet, the approach in question incurs a risk, namely that one fails to see the import of the combined, cumulative support the arguments provide. The aim of this paper has been to somewhat remedy that state of affairs.

\section{Notes}

${ }^{1}$ See, for example Joyce (2013), Kahane (2011), Mason (2010) and Griffiths and Wilkins.

${ }^{2}$ See, e.g., Mackie (1977, chapter 1) and Tolhurst (1987). I am also thinking of the skeptical arguments that have emerged in the debate about "peer disagreement". See Christiansen (2007), Feldman (2006), and Kelly (2005).

${ }^{3}$ For some instances of this strategy, see Joyce (2006a) and (2006b) and Street (2006). See also Ruse (1986).

${ }^{4}$ An alternative approach would be to explore if any of the dialectical machinery employed by the debunking strategy has a role to play also in arguments from disagreement. It does not matter which approach we choose. Any of them will allow us to cast light both on the role of the debunking strategy in arguments from disagreement and on the role of appeals to disagreement in the debunking strategy.

${ }^{5}$ I don't want to exclude entirely that the debunking strategy might work also in the case of areas without disagreement. But then some other consideration must play a similar role.

${ }^{6}$ By a "belief", I mean an instance of a certain psychological attitude. A belief should be distinguished from its content which is the proposition that constitutes its object. A belief is 
thus connected to a certain individual. However, if a proposition $p$ is the object both of a belief possessed by A and a belief possessed B we may say that they "share" belief (in $p$ ), in spite of the fact that their beliefs constitute distinct states.

${ }^{7}$ Some debunkers do not want to commit to a particular view about what makes a beliefforming defective. For example, Shaun Nichols does not want to choose between the view that a process is defective to the extent that it does not generally lead to true beliefs and the view that it is defective in virtue of being such that the resulting beliefs "aren't conditioned by the evidence" (Nichols $(2014,733)$.

${ }^{8}$ See Singer (1974) and (2005). For a critique, see Tersman (2008).

${ }^{9}$ Or at least all "positive" ones; beliefs that actually ascribe some moral status or property to something.

${ }^{10}$ The insertion of the word "discovery" is motivated by the internalist idea that the fact that our beliefs are caused by an "off-track" process is relevant to the credentials of the beliefs only if the subject is aware of it.

${ }^{11}$ Note that I am classifying Street as a debunker although she never explicitly uses the term "unjustified" (or any of its common cognates) when stating her argument. This is motivated by the fact that she thinks that the combination of the version of the evolutionary account she favors ("the adaptive link account") and a (non-naturalist) realist account of ethics generates a skeptical conclusion while still conceding that it does not rule out the truth of the target beliefs.

${ }^{12}$ Obviously, this type of argument works only to the extent that constructivism doesn't also have skeptical implications (when combined with the evolutionary account). This has recently been questioned. See Tropman (2014).

${ }^{13}$ Kahane stresses that the meta-ethical position he calls "objectivism" plays a central role in a debunking argument (see Kahane $(2010,103))$.

${ }^{14}$ There is, however, a background assumption I take to be essential, namely the cognitivist one that "moral beliefs" are indeed beliefs and thus capable of being true and false. Unless we make this assumption, it is hard to make sense for example of the idea that moral beliefs are unjustified in the sense relevant in this context. Cognitivism is an assumption that realism shares with some of its competitors, such as constructivism. One possibility is to use a debunking argument to undermine cognitivism generally on the ground that any meta-ethical view that shares it generates the conclusion that moral beliefs are unjustified.

${ }^{15}$ I acknowledge that this is a non-standard use of "reliable", at least in some contexts. In epistemology, "reliable" is usually reserved for a feature of belief-forming processes rather than of beliefs. However, in the context of the discussion of the debunking strategy my use is not uncommon. It is often the "reliability" of the target beliefs that debunkers are said to wish to undermine. See, e.g., Pummer $(2013,37)$. In any case, the definition is a stipulative one.

${ }^{16} \mathrm{He}$ acknowledges that only some moral truths may plausibly be held to be necessary, such as those that "that fix the conditions under which a concrete person, action, or event satisfies a moral predicate". However, this is arguably enough since he, to rebut the global debunker's challenge, only has to establish the credentials of a subset of our moral beliefs.

${ }^{17}$ Of course, those who advocate this account, including Joyce and Street, typically acknowledge that also other factors have been in play, such as historic contingencies or idiosyncratic personality traits. That is, they concede that the Darwinian factors are not 
sufficient to explain which specific beliefs we have ended up with, but only that they define a space in which the optional ones are found. However, they also stress that these additional factors do not essentially change the picture (because the assumption that they have had an impact is also morally neutral).

${ }^{18}$ This is a response Hartry Field hints at in some passages. See Field (1996, 375).

${ }^{19}$ Richard Joyce argues for the same conclusion. See Joyce (2016).

${ }^{20}$ Provided of course that $p$ represents a fact to which we can have perceptual access.

${ }^{21}$ She acknowledges that a realist can try to reconcile a non-skeptical view with an evolutionary account by invoking another version of the evolutionary account, namely the version according to which our moral beliefs are fitness-enhancing because they are often true ("the tracking account"). However, she argues that this version can independently be shown to be implausible on scientific grounds.

${ }^{22}$ A consideration can fail to make a proposition likely to be true without making it likely to be false. Consider, for example, my having an odd number of rabbits in my yard. This fact does not make it likely that the number of all existing rabbits in the world is odd. Nor does it of course make it likely that the number of existing rabbits is not odd.

${ }^{23}$ Clark-Doane's observation that some of the contents of our moral beliefs are, if true, true with metaphysical necessity, obviously provides a further complication for Street's argument.

${ }^{24}$ So, many observational beliefs have reliability support, in virtue of being reliable, while many theoretical scientific beliefs also have that type of support, due to the fact that their contents provides plausible explanations of the truth of the contents of observational beliefs.

${ }^{25}$ This view is a part of Field's version of the so-called Benacerraf challenge against Platonism in Mathematics, That challenge shares some but not all the features of a debunking argument. It seeks to show that our mathematical beliefs are not justified (given Platonism) through questioning their reliability. However, instead of appealing to some specific genealogical claim it merely refers to the difficulties of explaining (given Platonism) their reliability.

${ }^{26}$ See, e.g., Harman (1977) and (1986). For a prominent realist response, see Sturgeon (1988).

${ }^{27}$ See Harris (1977) and (1984).

${ }^{28}$ Of course, whether this really is so is difficult to determine before the theory has been worked out in detail. Perhaps moral facts have a role to play in the explanation of why we live in the way we do.

${ }^{29}$ Note that I am not insisting that this construal captures Mackie's own intentions. I would also like to add that although I think that some arguments from moral disagreement are best construed as debunking challenges, others can clearly not be squeezed into the format. They take quite different paths to their skeptical conclusions. See Tersman (2006) for further discussion (and see in particular chapter 3 for a discussion of Mackie's argument).

${ }^{30}$ See Joyce (2006b, 135), (2006a) and (2015).

${ }^{31}$ A central concept in Enoch's account is that of a fact being "responsible" for some other fact. Enoch takes this term to cover both a causal relation and "a metaphysical relation of constitution". It is the latter type of relation that is supposed to hold between the fact that an action promotes survival and the fact that it is right. Note, however, that, as Enoch rejects 
naturalism, the relation is not that of identity. For more about the type of relation Enoch has in mind, see $(2010,431)$.

${ }^{32} \mathrm{He}$ therefore suggests that the only way in which a non-skeptic can hope to accommodate the evolutionary account is to argue that it does, after all (when all the details are filled in) posit moral facts. Accordingly, he suggests that the non-skeptic must argue that the debunker and skeptic about the target beliefs cannot consistently accept the evolutionary account. As the discussion illustrates, I disagree. A skeptic can hope to reconcile the evolutionary account with her belief in the reliability of our moral beliefs, even given that it does not assume any moral facts. Thus, she does not have to argue that a skeptic cannot "really" accept that account. In other words, an evolutionary account can, as Enoch's proposal illustrates, be common ground for the skeptic and the non-skeptic.

${ }^{33}$ Incidentally, this is another point at which appeals to disagreement may help the debunker (by supporting the burden of proof-attribution).

${ }^{34}$ Of course, one might perhaps deny that one is committed to perceptual skepticism by dismissing attempts to defend the reliability of moral beliefs on the ground that they are circular, by pointing to some other difference between perceptual and moral beliefs. For example, one might stress that best account we have of our perceptual beliefs does, unlike in the moral case, assume their truth (in spite of it being circular when viewed as a defense of their reliability).

${ }^{35}$ This is stressed also by Joyce who in this context quotes a famous remark by Gilbert Harman. The remark concerns the possibility of responding to his well-known challenge against moral realism; i.e., the argument according to which we a reason to believe in moral facts only if moral facts are assumed by the best explanation of some observation. Harman stresses that, if one wants to disprove the claim that moral facts are not assumed by the best explanation of any observation, one must give a believable account of how moral facts are supposed to generate observations. See Harman $(1986,62)$.

${ }^{36}$ Note that logical consistency between the bridge principle and the contents of the target beliefs is accordingly not enough. They must also be "probabilistically consistent" in the sense that the bridge principle must not conflict with the conclusions that we are led to accept (by competent reasoning) through taking the contents of the target beliefs as starting points.

${ }^{37}$ An interesting upshot of this requirement is that, when we assess a debunking argument against our moral beliefs, we must determine which conclusions we reasonably may draw from the contents of the target beliefs. That is, we must engage in the very activity whose point the debunker tries to undermine.

${ }^{38}$ Note that the defense of the reliability that is available in the case of our perceptual beliefs satisfies both the above constraints.

${ }^{39}$ This is not to say, however, that the other constraints don't help to account for the relevance of disagreement at all. It could be argued, for example, that if the fact that the target process results in beliefs that conflict with each other this is itself sufficient for concluding that the first constraint is violated, as everything follows from an inconsistent set of beliefs (including the falsity of the pertinent bridge principle).

\footnotetext{
${ }^{40}$ Notice, again, that by a "belief" I am referring to an instance of a psychological attitude that is connected with a particular subject. A process can give rise to inconsistencies through leading to beliefs (held by different persons) whose contents are inconsistent.
} 
${ }^{41}$ The reason is obviously that a set of beliefs that contains many conflicts also contains many false beliefs. Presumably, whether the presence of such conflicts undermines the assumption that the pertinent factor is reliability-conferring depends on how frequent they are.

${ }^{42}$ For example, consider the debate about "peer disagreement". Everyone agrees that if we have reason to think that our opponents are not our peers, perhaps because they are less smart or well informed about relevant evidence, then their opposition gives us no reason to reduce our confidence in the contested beliefs.

${ }^{43}$ For more discussion about constraints of the relevant kind, see Tersman (2012).

\section{References}

Brosnan, K. (2011). "Do the evolutionary origins of our moral beliefs undermine moral knowledge?", Biology and Philosophy 26, 51-64.

Christensen, D. (2007). “Epistemology of Disagreement: The Good News”, Philosophical Review 116: 187-217.

Clark-Doane, J. (2015). “What is the Benacerraf Problem?”, in F. Pataut (ed.), New

Perspectives on the Philosophy of Paul Benacerraf: Truth, Objects, Infinity, forthcoming.

Enoch, D. (2010). "The epistemological challenge to metanormative realism: how best to understand it, and how to cope with it", Philosophical Studies 148, 413-38.

Feldman, R. (2006). “Epistemological Puzzles about Disagreement,” 216-36 in S.

Hetherington (ed.), Epistemology Futures. Oxford: Oxford University Press.

Field, H. (1989). Realism, Mathematics, and Modality. Oxford: Blackwell.

Field, H. (1996). “The A Prioricity of Logic”, Proceedings of the Aristotelian Society 96, 359-

79.

Griffiths, P. E. \& Wilkins, J. S., 'When Do Evolutionary Explanations of Belief Debunk

Belief?'. In P. R. Sloan (ed.), Darwin in the $21^{\text {st }}$ Century: Nature, Humanity, and God,

Notre Dame, Indiana: Notre Dame University Press, in press.

Harman, G. (1977), The Nature of Morality. New York: Oxford University Press, 1977. 
Harman, G. (1986). "Moral Explanations of Natural Facts - Can Moral Claims Be Tested Against Moral Reality?", Southern Journal of Philosophy 24 (suppl.): 57-68.

Harris, M. (1977). Cannibals and Kings, New York: Random House.

Harris, M. (1977). “Animal Capture and Yanamamo Warfare: Retrospect and New Evidence”, Journal. of Anthropological Research 40 (1984), 183-201.

Joyce, R. (2006a). The Evolution of Morality, Cambridge, Mass.: MIT Press.

Joyce, R. (2006b). 'Metaethics and the empirical sciences', Philosophical Explorations 9, 133- 48.

Joyce, R. (2013). ’The Evolutionary Debunking of Morality’, in J. Feinberg \& R. ShaferLandau (eds.), Reason and Responsibility, 15th edition, Cengage, in press.

Joyce, R. (2016), “Confessions of a modest debunker”, in Explanation in Mathematics and Ethics (eds. Leibowitz, U., and Sinclair, N.), Oxford: Oxford University Press, forthcoming.

Kahane G. (2011). 'Evolutionary Debunking Arguments,' Nous 45, 103-25.

Kelly, T. (2005). “The Epistemic Significance of Disagreement," Oxford Studies in Epistemology 1: 167-96.

Mason, K. (2010). 'Debunking Arguments and the Genealogy of Religion and Morality', Philosophical Compass 5/9, 770-8.

Nichols, S. (2014). "Process Debunking and Ethics”, Ethics 124, 727-49.

Pummer, T. (2013). “Intuitions about large number cases”, Analysis 73, 37-46.

Rawls, J. (1971). A Theory of Justice, Cambridge, Mass .: Harvard University Press.

Ruse, M. (1986). Taking Darwin seriously, Oxford: Blackwell.

Shafer-Landau, R. (2012). “Evolutionary Debunking, Moral Realism and Moral Knowledge”, Journal of Ethics \& Social Philosophy 7, 1-37.

Singer, P. (1974). "Sidgwick and Reflective Equilibrium”, The Monist 58, 490-517. 
Singer, P. (2005). “Ethics and Intuitions”, The Journal of Ethics 9, 331-352.

Street, S. (2006). “A Darwinian Dilemma for Realist Theories of Value”, Philosophical Studies 127, 109-66.

Sturgeon, N. (1986), “Moral Explanations”. Reprinted in G. Sayre-McCord (ed.), Essays on Moral Realism, Ithaca: Cornell University Press, 1988, 229-255.

Tersman, F. (2006). Moral Disagreement, New York: Cambridge University Press.

Tersman, F. (2008). “The Reliability of Moral Intuitions: A Challenge from Neuroscience”, Australasian Journal of Philosophy 86, 389-405.

Tersman, F. (2012). "Intuitional Disagreement”, Southern Journal of Philosophy 50, 639-659.

Tolhurst, W. (1987). “The Argument from Moral Disagreement”. Ethics 97, 610-21.

Tropman, E. (2014). "Evolutionary debunking arguments: Moral realism, constructivism, and explaining moral knowledge.” Philosophical Explorations 17: 126-140. 